\title{
CAPITAL ERÓTICO: UM ESTUDO DE MENSURAÇÃO
}

\author{
BALBINO, Isabela Santos ${ }^{1}$ \\ CIRIBELI, João Paulo ${ }^{2}$ \\ MASSARDI, Wellington de Oliveira ${ }^{3}$ \\ MENDES, Wanderson de Almeida ${ }^{4}$ \\ MENDES, Wesley de Almeida ${ }^{5}$
}

Recebido em: 2020.11.17 Aprovado em: 2021.01.22 ISSUE DOI: $10.3738 / 1982.2278 .3867$

RESUMO: O objetivo geral desse estudo é testar a validação do questionário capaz de identificar a presença do Capital Erótico nos perfis por meio de perguntas elaboradas especificamente embasadas nas seis variáveis que compõem o conceito, a saber: beleza, atratividade sexual e física, habilidades sociais, dinamismo, apresentação social e sexualidade. A metodologia utilizada para verificação foi à ferramenta estatística denominada Análise Fatorial, cujo método identifica os fatores de maior relevância e destaca as principais variáveis. Os dados foram tratados com auxílio do software SSPS, sendo entrevistados para análise 135 casos. Pode-se afirmar através dos resultados obtidos, que o questionário elaborado possui solidez e base suficientes para identificar se o indivíduo possui, de forma integral ou parcial, um conjunto de nove fatores que compõem o perfil do Capital Erótico (CE). Neste sentido, cabe ressaltar que o CE está presente nas pessoas, seja em maior ou menor grau, sendo assim identificar e quantificá-lo pode ser relevante ao indivíduo que busca aprimorá-lo para aplicar em seu progresso pessoal e profissional.

Palavras-chave: Beleza. Relacionamentos Interpessoais. Análise Fatorial.

\section{EROTIC CAPITAL: A MEASUREMENT STUDY}

SUMMARY: The general objective of this study is to test the validation of the questionnaire capable of identifying the presence of the Erotic Capital in the profiles through questions elaborated specifically based on the six variables that make up the concept, namely: beauty, sexual and physical attractiveness, social skills, dynamism, social presentation and sexuality. The methodology used for verification was the statistical tool called Factor Analysis, whose method identifies the most relevant factors and highlights the main variables. The data were treated with the aid of the SSPS software, and 135 cases were interviewed for analysis. It can be affirmed through the obtained results, that the elaborated questionnaire has enough solidity and base to identify if the individual has, in integral or partial form, a set of nine factors that compose the profile of the Erotic Capital. In this sense, it is worth noting that Erotic Capital is present in people, whether to a greater or lesser degree, so identifying and quantifying it can be relevant to the individual who seeks to improve it to apply it to their personal and professional progress.

Keywords: Beauty. Interpersonal Relationships. Factor Analysis.

\footnotetext{
${ }^{1}$ Graduada em Administração pela Faculdade Governador Ozanam Coelho (FAGOC).

${ }^{2}$ Doutor em Administração; Mestre em Gestão de Empresas; Especialista em Gestão da Informação no Agronegócio; Graduação em Administração com Habilitação em Adm. de Cooperativas pela UFV. Professor da UNIFAGOC.

${ }^{3}$ Mestre em Administração pela UFV. Graduado em Ciências Contábeis pela FAGOC.

${ }^{4}$ Doutorando e Mestre em Administração pela UFV; Especialista em Engenharia e Gerenciamento de Manutenção e MBA Executivo em Gestão de Produção e Qualidade pela UCAM; Graduado em Administração pela FAGOC.

${ }^{5}$ Doutor e Mestre em Administração pela UFV; Especialista em Gestão Empresarial e Planejamento Tributário pela UCAM; Bacharel em Administração pela Faculdade Governador Ozanam Coelho (FAGOC).
} 


\section{INTRODUÇÃO}

Vinícius de Moraes (1957) já dizia: "que me perdoem as feias, mas a beleza é fundamental". A preocupação com a imagem e a apresentação social não é uma questão recente. $\mathrm{Na}$ antiguidade, já era possível notar-se a importância ao culto da boa aparência e a forma física objetivando destaque na sociedade (HAKIM, 2012). A beleza já era vista como uma qualidade persuasiva, imponente, que poderia levar as pessoas a perceberem interesses mútuos, podendo ser julgados como indivíduos mais inteligentes e sociáveis (MADUREIRA; NOVAES; VILHENA, 2015).

Para os gregos, o corpo era valorizado pela sua capacidade física, saúde e fertilidade; por muitos anos, a valorização de uma imagem bela exprimia símbolo de saúde e perfeição (SIEBERT, 1995). Na Idade Média, os cuidados com o corpo e a imagem sofreram repressões por influência do catolicismo, uma vez que a carne era considerada apenas matéria, sendo um pecado cultuá-la.

O período de repressão não durou muito e, nos séculos seguintes, com o surgimento do período renascentista, uma nova visão do culto à imagem surgiu, e com ela a liberdade de expressão. A partir de 1900, a beleza física retomou o lugar de destaque na sociedade, e a liberdade para expor o corpo fez com que novos padrões estéticos fossem adotados. O culto à beleza generalizou-se definitivamente com a chegada da televisão, das revistas e novelas, e de outras formas de exibição, difundindo essa nova cultura entre as sociedades (GOLDENBERG; RAMOS, 2002; CASTRO, 2003).

Com a nova fase de exposição do corpo, surgiram novos conceitos e padrões que se difundiram, e, com o passar dos anos, tornou-se cada vez mais importante ter um corpo fisicamente bonito, uma pele saudável, boas maneiras, cortesia, educação, simpatia, vestir-se adequadamente, entre outras características que podem refletir na conquista de relacionamentos fluidos e sucesso profissional (MARTINS, 2010; COSTA, 2004).

Um termo recentemente criado para qualificar e definir esse conjunto de características que tem poder para aferir a vida pessoal e profissional de um indivíduo foi cunhado por uma socióloga inglesa como capital erótico. O conceito estabelecido por Hakim (2012) é oriundo de três capitais já existentes, descritos por Pierre Bourdieu (1986), que divulgou seus estudos, na década de 1980, sobre a influência dos capitais econômico, social e cultural para a vida dos indivíduos.

Nucleus, v.18, n.1, abr. 2021 
Uma pesquisa realizada no fim da década de 1990, nos Estados Unidos, identificou a existência de um "adicional por beleza", ganho por aqueles indivíduos considerados bonitos. O estudo revelou que pessoas consideradas feias ganhavam menos do que as que possuíam beleza mediana, e bem menos que mulheres e homens bonitos. Na América do Norte, homens atraentes ganham de $14 \%$ a $27 \%$ a mais do que os menos atraentes, e as mulheres, entre $12 \%$ a $20 \%$ a mais que as julgadas da mesma maneira (HAKIM, 2012; HARPER, 2000).

Tendo em vista que o capital erótico pode ser um fator adicional importante para os indivíduos, e principalmente de grande valia para aqueles que querem exercer cargos de chefia, tal como sugere Hakim (2012), o problema de pesquisa fica assim definido: quais os respectivos componentes do Capital Erótico são considerados relevantes para a sua mensuração? Entenda-se por relevantes a definição ou identificação das principais variáveis que compõem o entendimento de determinada realidade.

A partir da ideia de que o capital erótico pode ser usado por homens e mulheres e que pode exercer influências sobre a vida pessoal e profissional das pessoas, o objetivo geral deste estudo é validar, via Análise Fatorial (AF), o questionário elaborado para mensurar a presença de Capital Erótico (CE) em determinada população.

\section{REFERENCIAL TEÓRICO}

\subsection{Capital Erótico: Origem, Conceito e Definição}

Desde o início da civilização, nota-se a preocupação dos indivíduos pela procura por encaixar-se nos padrões de beleza estéticos designados pela mídia e sociedade. Para a psicologia social, a beleza física é citada como atributo de influência das relações interpessoais, sendo específica da interação interpessoal (MADUREIRA; NOVAES; VILHENA, 2015).

A beleza sempre foi um elemento crucial para os relacionamentos, pois é ela que define o grau de conforto, atração, bem-estar e satisfação de uma pessoa em relação a outra. Pessoas consideradas atraentes são notadas e se destacam entre muitos. Indivíduos física e socialmente atraentes têm um "quê" a mais, um encanto que lhes proporciona benefícios em aspectos pessoais e em suas profissões (HAKIM, 2012).

Percebia-se desde a antiguidade a busca por um corpo bonito e saudável. Os gregos foram pioneiros com os cuidados e atenção dados à estética e construção da imagem. Para eles, a beleza resumia em um estilo de vida, e não somente a beleza física em si. O homem grego considerado 
belo era aquele que possuía o hábito da prática de exercícios físicos, que aprendia música, política e apreciava o conhecimento e a arte (PRIORI, 2000).

Considerada a beleza como porta principal da possibilidade de obtenção de proveitos e prazer sexual, afirmada pela crença da vinculação da estética ao erótico, a aparência imposta pelos padrões rapidamente é adotada como a mais desejada, e consequentemente mais valorizada e cara, despertando o desejo de quem não tem e dando poder a quem possui (SAMPAIO; FERREIRA, 2009).

Segundo Knoop (2008), os indivíduos fazem uso de beleza e sensualidade como instrumentos para obtenção de proveito em suas relações interpessoais. Acredita-se popularmente que a beleza possui o poder de abrir portas no âmbito social e até mesmo influenciar o mercado de trabalho. Sendo assim, o indivíduo que souber usá-la em benefício próprio terá mais predicados que os demais concorrentes, e poderá ainda ter vantagens em contratações e relacionamentos interpessoais (PEREIRA; SANTOS, 2013).

Em 2012, a socióloga e pesquisadora inglesa Catherine Hakim lançou o livro em que descreve suas descobertas sobre as influências do comportamento humano para as relações sociais, afirmando existir um quarto atributo, o capital erótico, que está atrelado a três anteriormente conhecidos: o capital econômico, o capital cultural e o capital social. A autora é referência sobre o tema, em conceitos e pesquisas realizadas sobre sua hipótese, e seu livro foi utilizado como principal fonte de informações para este trabalho. Hakim (2012, p. 7) diz que pessoas atraentes são mais bem-sucedidas e define o quarto capital como:

Cunhei o termo "capital erótico" para aludir a uma obscura, embora crucial, combinação de beleza, sex appeal, capacidade de apresentação pessoal e habilidades sociais - uma união de atrativos físicos e sociais que torna alguns homens e mulheres companhias agradáveis e bons colegas, atraentes para todos os membros de sua sociedade e, especialmente para o sexo oposto.

O capital erótico exige algumas aptidões e habilidades, porém ele pode ser aprendido, desenvolvido e treinado. Na busca por vantagens num ambiente tão competitivo como o mercado de trabalho, o capital erótico pode ser desenvolvido e aprendido da mesma forma como alguém se capacita intelectualmente.

O primeiro e mais natural instrumento, objeto e meio técnico do homem é o seu corpo. Ele é a melhor ferramenta para aferir a vida social, ele se comunica com outros corpos e possui uma imagem e presença única característica de cada um, que exalam percepções e opiniões antes mesmo do "falar" (MAUSS, 2003). 
Um estudo realizado nos Estados Unidos e Grã-Bretanha objetivou medir o impacto da atratividade na interação face a face. A análise teve cunho nacional e forneceu dados representativos para esboçar informações confiáveis acerca da distribuição da atratividade entre homens, mulheres e crianças (HAKIM, 2012).

Foram feitas duas pesquisas principais: uma americana e outra canadense. Em ambas foi solicitado que os entrevistadores pontuassem os entrevistados em uma escala de cinco pontos, visando julgar seu nível de atração através de sua aparência e apresentação pessoal. Na pesquisa americana, os indivíduos selecionados retornaram para novas avaliações periodicamente em quatro anos, e, mesmo sendo avaliados por diferentes pessoas durante este período, houve uma concordância elevada acerca da opinião sobre sua aparência entre todos os entrevistadores (HAMERMESH; BIDDLE, 1994).

Nas entrevistas canadenses, o mesmo método foi utilizado, e, pelo mesmo período de quatro anos, as pessoas avaliadas foram apontadas de forma idêntica. A pesquisa concluiu que nove em cada dez pessoas avaliadas em ambos os estados foram classificadas igualmente acerca da atratividade que aparentavam possuir durante o período de estudo (HARPER, 2000).

Portanto, a pesquisa concluiu que cada indivíduo impacta as demais pessoas de forma única e particular, e que a beleza possuída por cada indivíduo reflete na imagem criada pela sociedade. Por fim, a análise revela que a importância dada aos sexos varia à medida que envelhecem, o que torna a maioria das pessoas mais atraentes e agradáveis. As Tabelas 1 e 2 exibem os resultados obtidos nesses estudos.

Tabela 1- Distribuição da aparência de crianças na Grã-Bretanha, década de 1960.

\begin{tabular}{|c|c|c|c|c|}
\hline & \multicolumn{2}{|c|}{ Idade 7} & \multicolumn{2}{|c|}{ Idade 11} \\
\hline & $H$ & $M$ & $H$ & $M$ \\
\hline Atraente & $51 \%$ & $57 \%$ & $45 \%$ & $56 \%$ \\
\hline Comum & $42 \%$ & $36 \%$ & $47 \%$ & $35 \%$ \\
\hline Não Atraente & $7 \%$ & $7 \%$ & $8 \%$ & $9 \%$ \\
\hline Número de pesquisados & 5.605 & 5.798 & 5.605 & 5.798 \\
\hline
\end{tabular}

Fonte: adaptada pelos autores com base em Harper (2000).

Tabela 2 - Distribuição da aparência nos Estados Unidos e no Canadá, década de 1970.

\begin{tabular}{lcccccc}
\hline & \multicolumn{2}{c}{1971} & \multicolumn{2}{c}{1977} & \multicolumn{2}{c}{$1977-1981$} \\
\cline { 2 - 7 } & $\mathrm{H}$ & $\mathrm{M}$ & $\mathrm{H}$ & $\mathrm{M}$ & $\mathrm{H}$ & $\mathrm{M}$ \\
\hline 1- Extremamente bonito & $2,9 \%$ & $2,9 \%$ & $2,9 \%$ & $2,9 \%$ & $2,9 \%$ & $2,9 \%$ \\
2- Acima da média & $24,2 \%$ & $28,1 \%$ & $28,1 \%$ & $28,1 \%$ & $28,1 \%$ & $28,1 \%$ \\
3- Na média para a idade & $60,4 \%$ & $51,5 \%$ & $51,5 \%$ & $51,5 \%$ & $51,5 \%$ & $51,5 \%$ \\
4- Abaixo da média para a idade & $10,8 \%$ & $15,2 \%$ & $15,2 \%$ & $15,2 \%$ & $15,2 \%$ & $15,2 \%$ \\
5- Feio & $1,7 \%$ & $2,3 \%$ & $2,3 \%$ & $2,3 \%$ & $2,3 \%$ & $2,3 \%$ \\
Número de pesquisados & 864 & 1.194 & 1.194 & 1.194 & 1.194 & 1.194 \\
\hline
\end{tabular}

Fonte: Adaptada pelos autores com base em Hamermesh e Biddle (1994, p. 1180). 
Estudo mais recente de Schlösser e Camargo (2019) aponta 6 classes sobre a percepção da beleza física, sendo a principal dela "saúde e bem-estar", que está relacionada aos cuidados com o corpo, com a alimentação e com a mente, fatores que elevarão a autoestima e a autoconfiança contribuindo assim para a felicidade e sucesso profissional. Segundo os autores, "a partir do contato social [...] as imagens que se ancoram à beleza fazem referência ao sucesso, influência social, maior atratividade, bem como à saúde e bem-estar" (SCHLÖSSER; CAMARGO 2019, p.89).

Em 1983, o sociólogo francês Pierre Bourdieu afirmou a existência de três tipos de atributos pessoais que exerciam influência sobre os indivíduos: capital econômico, cultural e social. (HAKIM, 2012). Pode-se, a partir dessa definição feita por Bourdieu (1986), determinar caraterísticas e finalidades para cada capital (Quadro 1).

Quadro 1 - Capitais segundo Pierre Bourdieu.

\begin{tabular}{|c|l|}
\hline CAPITAL & \multicolumn{1}{c|}{ DEFINIÇÃO } \\
\hline $\begin{array}{c}\text { Capital } \\
\text { Econômico }\end{array}$ & $\begin{array}{l}\text { É a soma dos recursos e habilidades que as pessoas usam para produzir ganhos financeiros - } \\
\text { como dinheiro, terras ou imóveis. }\end{array}$ \\
\hline $\begin{array}{c}\text { Capital } \\
\text { Cultural }\end{array}$ & $\begin{array}{l}\text { O capital cultural inclui o capital humano e este é definido pelos economistas através de } \\
\text { qualificações educacionais, treinamento, habilidades e experiência profissional, que são } \\
\text { valiosos no mercado de trabalho e podem ser usados para obter rendimentos. }\end{array}$ \\
\hline $\begin{array}{c}\text { Capital } \\
\text { Social }\end{array}$ & $\begin{array}{l}\text { O capital social é a soma de recursos, reais ou potenciais, que passam a pertencer a uma pessoa } \\
\text { ou um grupo a partir de seu acesso a uma rede de relacionamentos ou do ingresso em uma } \\
\text { comunidade, tribo ou clube para produzir relacionamentos úteis. }\end{array}$ \\
\hline
\end{tabular}

Fonte: Adaptada pela autora com base em Hakim, 2012 e Bourdieu 1986.

\subsection{Componentes do capital erótico}

Descrito como um elemento multifacetado por Hakim (2012), o capital erótico mostra-se um fator proeminente, ou seja, encontra-se acima de épocas ou sociedades. Estudos como os de Bourdieu (1986), Caballo (2006), Knoop (2008) e Madureira, Novaes e Vilhena (2015) demonstram a existência de uma característica ainda desconhecida e anônima desde os primórdios, que qualificava e oferecia vantagens a determinados indivíduos que se destacavam na sociedade por conta deles.

A autora destaca a existência de seis ou sete (no caso das mulheres) elementos que compõem a essência do chamado capital erótico, os quais estão descritos no Quadro 2. 
Quadro 2 - Componentes do Capital Erótico

\begin{tabular}{|c|l|}
\hline COMPONENTES & \multicolumn{1}{c|}{ DESCRIÇÃO } \\
\hline Beleza & $\begin{array}{l}\text { Refere-se a um conjunto físico harmônico, atraente e agradável aos olhos, a uma } \\
\text { combinação de traços específicos, como olhos grandes, simetria corpórea, lábios } \\
\text { grossos, tom de pele e rosto “esculpido". }\end{array}$ \\
\hline $\begin{array}{c}\text { Atratividade Sexual } \\
\text { e Física }\end{array}$ & $\begin{array}{l}\text { Refere-se a um corpo simétrico e sexy, enquadrado nos padrões valorizados pela } \\
\text { sociedade. Também denominado sex-appeal, este elemento varia de acordo com a } \\
\text { personalidade. }\end{array}$ \\
\hline Habilidades sociais & $\begin{array}{l}\text { Refere-se à capacidade de interação do indivíduo, à habilidade de conquistar pessoas, } \\
\text { de gerar interesses. Está ligado ao charme, graça, e exclusivamente à socialização. }\end{array}$ \\
\hline Dinamismo & $\begin{array}{l}\text { Diz respeito ao misto composto por bom humor, energia social e boa forma física, } \\
\text { dinamismo pode ser exibido através da dança ou atividades esportivas. }\end{array}$ \\
\hline Apresentação social & $\begin{array}{l}\text { Está presente na forma de se vestir, no corte de cabelo, perfumes, joias, maquiagem e } \\
\text { outros acessórios utilizados para demonstrar estilo e status social. }\end{array}$ \\
\hline Sexualidade & $\begin{array}{l}\text { Relaciona-se com a competência sexual em si, diversão, imaginação erótica, energia, e } \\
\text { tudo mais que compõe um parceiro sexualmente satisfatório. }\end{array}$ \\
\hline
\end{tabular}

Fonte: Adaptado pelos autores com base em Hakim (2012); Bourdieu (1986); Caballo (2006); Knoop (2008); Eco (2011); Sones (2004); Madureira; Novaes; Vilhena (2015).

O conceito de beleza relaciona-se com a influência da atração sobre o modo como as pessoas veem, pensam e percebem umas às outras. Eco (2011) diz que o belo foi um adjetivo sempre usado para demonstrar aquilo que agrada aos olhos do espectador, para descrever o que é gracioso, bonito, justo e sublime. Enxerga-se o laço que liga o que é belo ao bom, portanto o que é belo é visto como gracioso e bom, enquanto o feio se mostra mau e defeituoso (SONES, 2004).

Atualmente a beleza é associada a uma tríade composta por: corpo definido, juventude e saúde, estando tais elementos interligados entre si mutualmente. (MADUREIRA; NOVAES; VILHENA, 2015). A atratividade sexual, que é o segundo componente definido por Hakim, pode ser evidenciada na forma explícita da fala e do comportamento de um indivíduo, na forma como se movimenta, anda, gesticula; está no olhar e nos gestos corpóreos notados.

A atratividade física é vista é como um elemento visível, de que os indivíduos dispõem para fazer julgamentos e formar opiniões acerca de personalidade, estilo, status e posição social (KNOOP, 2008). O terceiro elemento é denominado habilidade social e é apontado como o comportamento socialmente hábil emitido por um indivíduo e um contexto interpessoal específico, como o conjunto de comportamentos que exprimem sentimentos, desejos, opiniões, atitudes e direitos conforme adequados a cada situação (CABALLO, 2006).

Apontado como quarto componente, o dinamismo é uma característica percebida através da vitalidade, espontaneidade e animação para lidar com as mais diversas situações afetivas e profissionais vivenciadas diariamente. A pessoa dinâmica possui mais "holofotes" voltados para ela, pois despertam interesse em serem ouvidas e são mais percebidas em um ambiente de contatos e relacionamentos. (HAKIM, 2012). 
Acredita-se que uma boa imagem e impressão podem "abrir portas". Assim, Pereira e Santos (2013) dizem que a beleza bem capitalizada aumenta as chances de vantagem competitiva sobre os demais indivíduos que não utilizam a sua imagem para impressionar e deixar boas recordações. Nesse contexto, pode-se compreender a importância do quinto componente do capital erótico, denominado apresentação social.

O sexto e último componente que define o termo capital erótico, cunhado pela socióloga Catherine Hakim, é a sexualidade. Weeks (1995) relata que o corpo é visto como ponte para o julgamento final sobre quem, o que somos ou podemos nos tornar. $\mathrm{O}$ autor evidencia que as necessidades e desejos dos indivíduos de modificam por diversos fatores e principalmente devido à inconstância do corpo humano.

Alguns autores consideram ainda a existência de um sétimo e último componente do capital erótico. Algumas sociedades creem que a fertilidade é o sétimo adicional, exclusivo das mulheres, já que os homens não são capazes de engravidar. Porém, no contexto deste artigo, não consideraremos esse elemento na pesquisa, pois serão avaliados os perfis de homens e mulheres em total igualdade, sem adicionar vantagem a nenhum dos sexos (PEREIRA; SANTOS, 2013; HAKIM, 2012).

\subsection{Beleza, poder e carreira}

A aparência estética revela ter um determinante papel nos mais diversos processos de socialização e construção da identidade, podendo exercer um importante papel sobre o poder de vetar perfis, formas, padrões, estilos e várias outras características explícitas pela sociedade moderna (SAMPAIO; FERREIRA, 2009). Nos dias de hoje, mesmo desfrutando de perfeita saúde, se o corpo não estiver "perfeito", os indivíduos devem buscar submeter-se a correções e transformações para estar vinculados a padrões impostos pela mídia (MALYSSE, 2002).

Ocorreram profundas mudanças nos padrões e na forma de utilizar-se o corpo a partir da década de 1960. Com a expansão da indústria cultural, o corpo começou a ser exposto, passando a ser alvo de opiniões sobre a estética. Padrões e formas começaram a ser idealizados, e ao longo dos séculos são cultuados e adotados como objetivo para ser reconhecido na sociedade e ocupar um lugar de destaque (AVELAR; VEIGA, 2011).

Estudos realizados em Buenos Aires, na Argentina, evidenciam a intensa relação entre beleza e uma boa apresentação social a maiores chances de contratações no mercado de trabalho. De acordo com a pesquisa, foram enviados para várias empresas onde havia anúncios de vagas 
nas mais diferentes áreas, currículos fictícios com fotos de rostos atraentes e outros pouco atraentes. Nessa pesquisa, constatou-se que as pessoas atraentes recebiam em média $36 \%$ mais retornos e chamadas para entrevistas do que as consideradas menos atraentes; além disso, o contato feito pelas empresas contratantes ocorriam bem mais cedo para as pessoas consideradas atraentes do que para as demais. (LÓPEZ BÓO; ROSSI; URZUA, 2012).

$\mathrm{Na}$ cultura brasileira, observa-se que a beleza e o charme constituem lugares privilegiados para a construção de um perfil de destaque, a sociedade deseja, cultua e idolatra padrões, personalidades, formas e estilos julgados ideais para obtenção de sucesso pessoal e profissional (MARTINS; PEROSA, 2011). Hoje, em indústrias e nas mais diversas entidades de comércio e prestação de serviço, os sistemas são informatizados, estando o marketing fortemente ligado à tecnologia e à transmissão de informações através da mídia e da internet, que são utilizadas para expor e comercializar seus produtos. Sendo assim, houve uma supervalorização da imagem atraente e bela para a execução de tais funções (GOMES, 2010).

\section{MÉTODO}

Quanto ao tratamento dos dados, a pesquisa utilizou o método quantitativo, pois as informações recolhidas foram transformadas em números, classificando e analisando estatisticamente a amostra pesquisada (MORESI, 2003). Quanto à natureza, o estudo classificouse como aplicado, uma vez que os estudantes foram analisados com objetivo de identificar quais variáveis eram consideradas importantes e relevantes para compor o questionário capaz de mensurar a presença e nível de Capital Erótico - CE em um determinado perfil.

Quanto aos fins, a pesquisa é exploratória; quanto aos meios bibliográfica e estudo de caso intrínseco. Bibliográfica, pois foi elaborada por meio de materiais já existentes, encontrados através de artigos científicos e livros (GIL, 2002) e estudo de caso por buscar uma análise mais detalhada sobre terminada situação e seus aspectos, visto que tais condições favoreceram um conhecimento mais amplo e profundo acerca do objeto analisado (GIL, 2008).

O método de pesquisa utilizado para tratar os dados e revelar a validação do questionário pelas suas variáveis foi a técnica de Análise Fatorial, ferramenta estatística que busca explicar através de um determinado número de fatores a veracidade de um fato, determinando-se ainda um número reduzido de conteúdo para sua explicação (HAIR JR. et al., 2009). Dá-se o nome de fator, uma combinação linear de variáveis, onde extrai-se da essência do questionário, os fatores mais relevantes e válidos para a mensuração (HAIR JR. et al., 2009). 
O objetivo da Análise Fatorial é substituir um número inicial de variáveis, segmentandoas por um conjunto de menor número, determinado fatores, de modo a identificar a interdependência entre elas, objetivando uma compreensão e interpretação mais compreensível partindo das opiniões (número de entrevistados) versus assertivas (MINGOTI, 2005; PESTANA; GAGEIRO, 2008). Considera-se que o CE é uma variável latente, não podendo ser visualizada diretamente, mas afirmada por meio de fatores que justificam sua existência.

Para aplicação da Análise Fatorial foram verificados alguns critérios: 1. Consistência interna das questões por meio do coeficiente alfa de Cronbach, visando avaliar a qualidade (consistência interna) do questionário - valores próximos de 1, sendo aceitável valores iguais ou superiores a 0,6 para pesquisas exploratórias; 2. Teste de esfericidade de Barlett - testa a hipótese de que a matriz de correlação é uma matriz identidade; 3. Teste estatístico KMO (Kaiser-MeyerOklin) - Medida de adequação da amostra que permite avaliar quão adequada é a aplicação da Análise Fatorial (os valores de adequação compreendem entre 0,5 e 1,0), estes valores permitem realizar uma análise do poder de explicação dos fatores em relação a cada variável (MINGOTI, 2005; PESTANA; GAGEIRO, 2008; HAIR JR. et al., 2009).

Os dados foram obtidos através de questionário com 25 perguntas fechadas, elaboradas a partir das seis variáveis (HAKIM, 2012) que compõem o conceito do capital erótico, objetivando identificar a presença desses componentes nos perfis analisados. O questionário foi embasado pelo método de Likert, segundo o qual os alunos responderam às questões em uma escala variando de 1 (discordo totalmente) a 7 (concordo totalmente).

Foram entrevistados 135 alunos (amostra) de uma população de 229 estudantes regularmente matriculados no curso de administração da Faculdade Governado Ozanam Coelho FAGOC, localizada na cidade de Ubá, Minas Gerais. Hair Jr. et al. (2009) afirmam que populações iguais ou acima de 100 unidades deve-se considerar a aplicação do instrumento em pelo menos 50 unidades amostrais. Os questionários foram aplicados em sala de aula durante o mês de maio de 2016 a uma amostra considerada do tipo não probabilística.

\section{RESULTADO E DISCUSSÃO}

Este estudo consiste na elaboração de questionário valendo-se de critérios teóricos, metodológicos e empíricos. Nesta perspectiva a Análise Fatorial serviu para avaliar quais variáveis seriam mais adequadas para compor a técnica de coleta de dados (questionário).

Nucleus, v.18, n.1, abr. 2021 
Para testar a consistência das informações apontadas pelo questionário, calculou-se o Alfa de Cronbach, ferramenta capaz de mensurar a confiabilidade de um questionário através de correlações encontradas entre as perguntas e respostas, ele é calculado pela variância individual de cada item e da soma das variâncias encontradas sobre cada item avaliador. $\mathrm{O}$ valor mínimo para o questionário ser considerado confiável, são resultados acima de 0,70 (HAIR JR. et al., 2009); e neste teste o valor obtido foi de $\alpha=0,809$ (Tabela 3 ).

Tabela 3 - Aplicação do alfa de Cronbach

\begin{tabular}{cc}
\hline Cronbach's Alpha & $\mathrm{N}^{\circ}$ variáveis \\
\hline 0,809 & 25 \\
\hline
\end{tabular}

Fonte: Dados da pesquisa.

Na Tabela 4, o teste de Kaiser - Mayer- Oklin (KMO) mensurou o valor de 0,705. Segundo Hutcheson e Sofroniou (1999) a escala para interpretar o valor teste KMO deve estar entre 0,90 e 1 para excelente; de 0,80 a 0,89 para bom, entre 0,70 e 0,79 na média; de 0,60 a 0,69 para medíocre; entre 0,50 e 0,59 para ruim, e entre 0 e 0,49 para inadequado. Pallant (2007) sugere unicamente o valor de 0,60 como limite razoável para a análise, para tal, o valor do teste de KMO e Barlett encontrado deste artigo indica adequação mediana para as variáveis testadas.

A Tabela 5 de anti-imagem revela que $4 \%$ das variáveis apresentaram coeficiente acima de 0,80 (P17), 44\% apresentaram coeficiente acima de 0,70 (P03, P04, P05, P06, P07, P10, P12, P13, P14, P18, P24), 32\% apresentaram coeficiente acima de 0,60 ( P01, P02, P08, P15, P16, P20, P21, P23), 16\% apresentaram coeficiente acima de 0,50 (P09, P11, P19, P22), os 4\% restantes possuem coeficiente acima de 0,40 (P25), o que revela uma razoável relação entre os fatores em amostra e as variáveis avaliadas pela AF.

Tabela 4- Teste de KMO e Barlett

\begin{tabular}{ccc}
\hline \multicolumn{2}{c}{ Medida Kaiser-Meyer-Olkin de adequação de amostragem } & 0,705 \\
\hline Teste de esfericidade Barlett & Chi-quadrado aprox. & 1083,719 \\
\hline Df & 300 \\
\hline Sig. & 0,000 \\
\hline
\end{tabular}

Fonte: Dados da pesquisa, 2016.

A única pergunta com valor abaixo de 0,5 é a P25, com valor de comunalidade na ordem de 0,487 . Tal fato expressa uma inadequada utilização deste coeficiente. 
O número de fatores selecionados para o estudo são 9, conforme critério estabelecidos no Gráfico screeplot para a análise fatorial (ver Figura 1) que explicam cerca de 69,02\% da variância total. Pode-se identificar que, a partir do nono ponto os fatores exprimem um poder de explicação baixo em relação a variância total dos dados, assumindo valores percentuais muito próximos a partir dele.

Figura 1- Gráfico screeplot (análise fatorial)

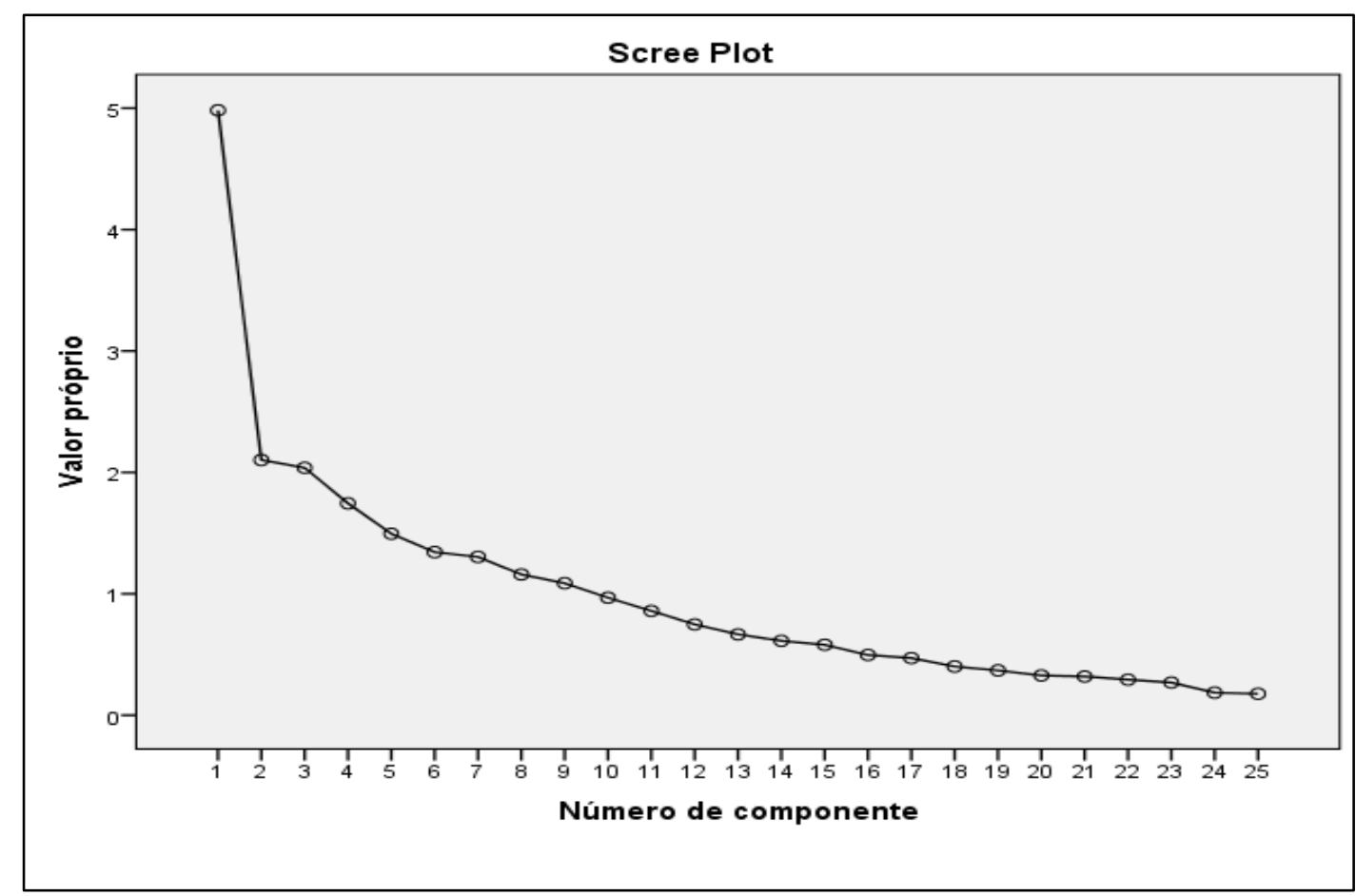

Fonte: Dados da pesquisa.

Nucleus, v.18, n.1, abr. 2021 
Tabela 5- Matriz anti- imagem

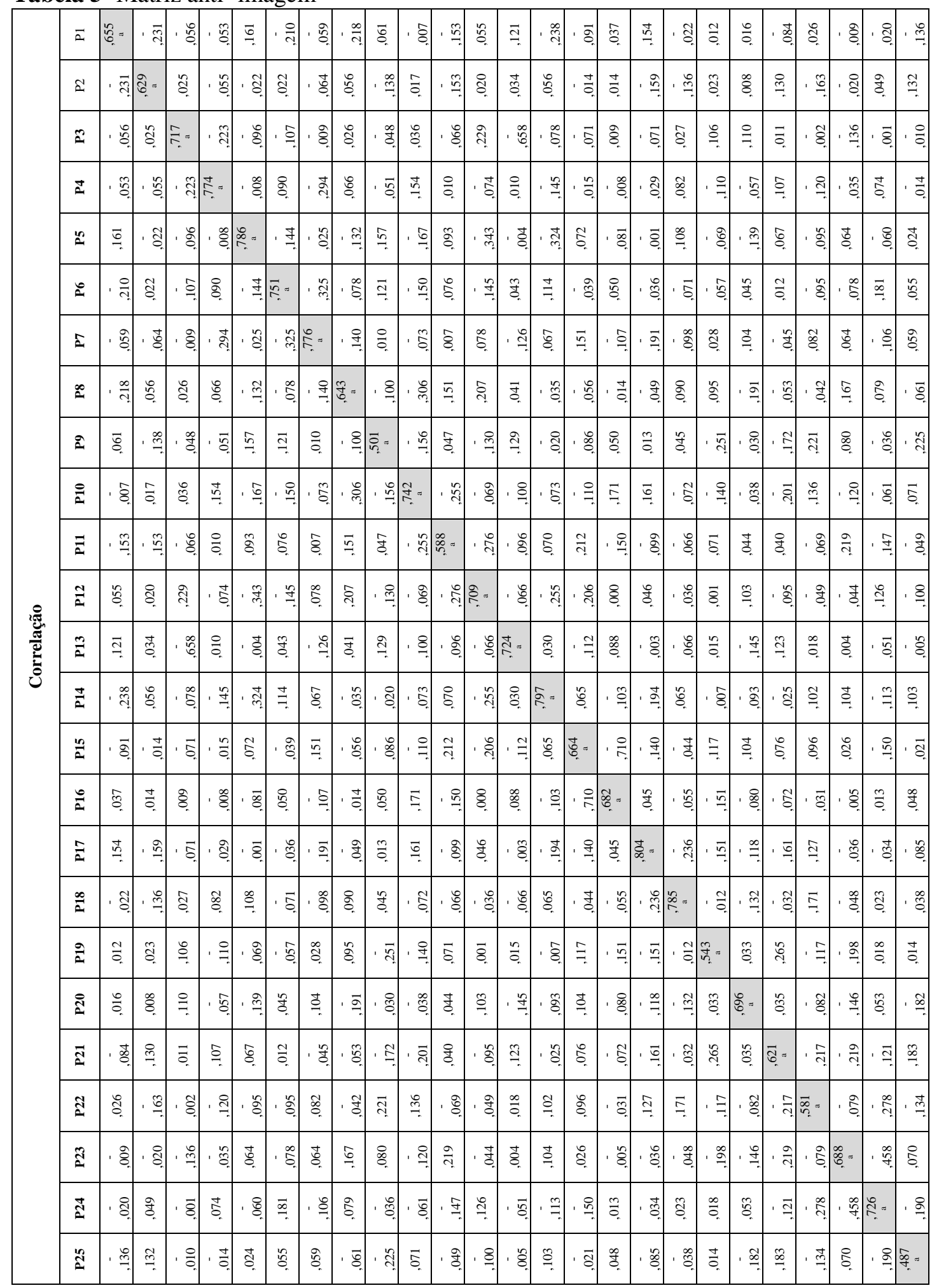

Fonte: Dados da pesquisa.

Nota: Extração pelo método de Varimax com normalização de Kaiser.

A partir daí observa-se a variância dos dados em torno dos fatores analisados para a mensuração da relação entre as variáveis e o nível encontrado de capital erótico nos perfis (Tabela 6). Na Tabela 7 é possível visualizar matriz de componente rotativa realizada no estudo. 
Partindo do agrupamento dos resultados obtidos pelas variáveis analisadas pode-se afirmar que o nível de capital erótico elevado está presente nos seguintes fatores em destaque:

Fator 1- Hábitos alimentares saudáveis e prática de atividade física = Pode-se afirmar que há um forte tendenciamento às respostas relacionadas com a prática regular de atividades físicas e com a preocupação em manter-se uma alimentação equilibrada, evitando-se exageros em bebidas e doces. Partindo dessa premissa pode-se concluir que um indivíduo que mantém uma dieta regrada e pratica atividades físicas regularmente possui um nível mais elevado da presença de capital erótico afirmado por esse fator (SIEBERT, 1995).

Tabela 6 - Variância total explicada (9 fatores)

\begin{tabular}{|c|c|c|c|c|c|c|c|c|c|}
\hline \multirow{2}{*}{  } & \multicolumn{2}{|c|}{$\begin{array}{c}\text { Valores próprios } \\
\text { iniciais }\end{array}$} & \multicolumn{4}{|c|}{ Carregamentos ao quadrado } & \multicolumn{3}{|c|}{ Carregamentos ao quadrado } \\
\hline & Total & $\begin{array}{c}\% \text { de } \\
\text { variação }\end{array}$ & $\begin{array}{c}\% \text { de } \\
\text { cumulativa }\end{array}$ & Total & $\begin{array}{c}\% \text { de } \\
\text { variação }\end{array}$ & $\begin{array}{c}\% \text { de } \\
\text { cumulativa }\end{array}$ & Total & $\begin{array}{c}\% \text { de } \\
\text { variação }\end{array}$ & $\begin{array}{c}\% \text { de } \\
\text { cumulativa }\end{array}$ \\
\hline 1 & 4,983 & 19,930 & 19,930 & 4,983 & 19,930 & 19,930 & 2,690 & 10,760 & 10,760 \\
\hline 2 & 2,103 & 8,408 & 28,338 & 2,102 & 8,408 & 28,338 & 2,395 & 9,581 & 20,341 \\
\hline 3 & 2,038 & 8,151 & 36,489 & 2,038 & 8,151 & 36,489 & 2,268 & 9,073 & 29,413 \\
\hline 4 & 1,745 & 6,981 & 43,470 & 1,745 & 6,981 & 43,470 & 2,094 & 8,376 & 37,789 \\
\hline 5 & 1,495 & 5,979 & 49,449 & 1,495 & 5,979 & 49,449 & 1,928 & 7,713 & 45,502 \\
\hline 6 & 1,344 & 5,375 & 54,824 & 1,344 & 5,375 & 54,824 & 1,562 & 6,247 & 51,749 \\
\hline 7 & 1,304 & 5,216 & 60,040 & 1,304 & 5,216 & 60,040 & 1,546 & 6,183 & 57,932 \\
\hline 8 & 1,160 & 4,638 & 64,678 & 1,160 & 4,638 & 64,678 & 1,437 & 5,746 & 63,678 \\
\hline 9 & 1,087 & 4,349 & 69,028 & 1,087 & 4,349 & 69,028 & 1,337 & 5,350 & 69,028 \\
\hline 10 & 0,968 & 3,872 & 72,900 & & & & & & \\
\hline 11 & 0,859 & 3,437 & 76,337 & & & & & & \\
\hline 12 & 0,748 & 2,993 & 79,330 & & & & & & \\
\hline 13 & 0,666 & 2,665 & 81,995 & & & & & & \\
\hline 14 & 0,613 & 2,451 & 84,446 & & & & & & \\
\hline 15 & 0,580 & 2,321 & 86,767 & & & & & & \\
\hline 16 & 0,496 & 1,984 & 88,751 & & & & & & \\
\hline 17 & 0,471 & 1,882 & 90,634 & & & & & & \\
\hline 18 & 0,401 & 1,606 & 92,239 & & & & & & \\
\hline 19 & 0,369 & 1,476 & 93,715 & & & & & & \\
\hline 20 & 0,327 & 1,309 & 95,025 & & & & & & \\
\hline 21 & 0,319 & 1,276 & 96,301 & & & & & & \\
\hline 22 & 0,293 & 1,172 & 97,473 & & & & & & \\
\hline 23 & 0,269 & 1,076 & 98,549 & & & & & & \\
\hline 24 & 0,186 & 0,744 & 99,293 & & & & & & \\
\hline 25 & 0,177 & 0,707 & 100,000 & & & & & & \\
\hline
\end{tabular}

Fonte: Dados da pesquisa.

Nota: Método de extração por análise do componente principal.

Fator 2- Habilidades sociais e apresentação $=\mathrm{O}$ fator 2 aponta um nível de capital erótico maior nos indivíduos que afirmam que são pessoas comunicativas, despojadas, simpáticas, bem-humoradas e ainda sim, que preocupam-se com a forma de se vestir, comportar e 
conversar com os demais. Indivíduos com uma boa habilidade de comunicação bem desenvolvida destacam-se mais pela capacidade de presença e cativa que possuem (HAKIM, 2012).

Fator 3- Atividade Sexual e Criatividade = É notório e ressaltado nesse terceiro fator a importância e manutenção da saúde sexual dos indivíduos, a Análise Fatorial evidenciou através da relevância nas questões P21, P22, P23, P24; Weeks (1995) relata que pessoas que mantém uma vida sexual ativa, inovam em seus relacionamentos, gostam de sair da rotina e são criativos no sexo e possuem um nível considerado de CE presentes em sua personalidade.

Tabela 7 - Matriz de componente rotativa

\begin{tabular}{|c|c|c|c|c|c|c|c|c|c|}
\hline \multicolumn{10}{|c|}{ Componentes } \\
\hline & 1 & 2 & 3 & 4 & 5 & 6 & 7 & 8 & 9 \\
\hline P13 & 0,842 & & & & & & & & \\
\hline P3 & 0,840 & & & & & & & & \\
\hline $\mathbf{P 4}$ & 0,543 & & & & & & & & \\
\hline \multicolumn{10}{|l|}{ P7 } \\
\hline P12 & & 0,812 & & & & & & & \\
\hline P5 & & 0,732 & & & & & & & \\
\hline P14 & & 0,637 & & & & & & & \\
\hline P10 & & 0,531 & & & & & & & \\
\hline $\mathbf{P 2 3}$ & & & 0,806 & & & & & & \\
\hline P24 & & & 0,775 & & & & & & \\
\hline $\mathbf{P} 21$ & & & 0,668 & & & & & & \\
\hline $\mathbf{P 2 2}$ & & & 0,607 & & & $-0,510$ & & & \\
\hline P8 & & & & 0,823 & & & & & \\
\hline P6 & & & & 0,556 & & & & & \\
\hline P15 & & & & & 0,866 & & & & \\
\hline P16 & & & & & 0,858 & & & & \\
\hline P18 & & & & & & 0,698 & & & \\
\hline \multicolumn{10}{|l|}{ P17 } \\
\hline $\mathbf{P 2}$ & & & & & & & 0,752 & & \\
\hline P1 & & & & 0,534 & & & 0,567 & & \\
\hline P11 & & & & & & & 0,520 & & \\
\hline P20 & & & & & & & & 0,541 & \\
\hline \multicolumn{10}{|l|}{ P9 } \\
\hline P19 & & & & & & & & & 0,807 \\
\hline
\end{tabular}

Fonte: Dados da Pesquisa,2016.

Método de Extração: Análise do Componente Principal; Rotação Convergida em 17 iterações.

Fator 4- Atração, Carisma e Beleza = Neste fator pode-se identificar que as pessoas que possuem um conjunto físico harmônico atraente e agradável aos olhos demonstram ter o nível maior de CE frente as variáveis questionadas e apontadas na Análise Fatorial em P01, P06 e P08 
como questão de relevância, onde foi sub julgado importante para a composição de um perfil visivelmente atraente (KNOOP, 2008).

Fator 5- Dinamismo e Flexibilidade =Identificou-se nesta análise a evidência de um indivíduo ser flexível e capaz de aceitar facilmente opiniões, influencias de pessoas e do ambiente externo. Apontado na P15 e P16, o fator revela a importância de um indivíduo possuir energia social, alegria e animação capazes de ser percebidas pelos outros (PEREIRA; SANTOS, 2013).

Fator 6- Estilo e Versatilidade $=$ O Fator concluiu através das variáveis apontadas em P18 e P22 que os indivíduos que são considerados práticos, versáteis, que possuem um estilo próprio, são desapegados e apresentam ainda, traços de personalidade mutáveis são pessoas que estão mais próximas do fator 6 relevante que identificou a presença e um nível maior de CE no perfil (HAKIM, 2012).

Fator 7- Bom Humor, Imagem e Conforto = No sétimo fator apontado para a presença de um nível maior de CE afirma que o indivíduo que se cuida esteticamente em prol de manter uma pele bonita, saudável, que utiliza de tratamentos para melhorar a estética facial por exemplo, é capaz de passar mais credibilidade em relacionamentos afetivos onde outras pessoas se sentem mais confortáveis em se abrir e conversar. Avelar e Veiga (2011) concordam que uma imagem agradável aos olhos é capaz de quebrar resistências e facilitar o interesse e gerar conforto nos outros indivíduos.

Fator 8- Presença e Apresentação Social = Neste fator ressaltou-se a importância de um indivíduo saber se comportar, falar, se vestir, possuir uma postura correta e saber apresentar-se bem perante outros. As questões P20 e P25 destacam estas características em um perfil que possui o CE mais presente, Caballo (2006) afirma que indivíduos que desenvolvem melhor essas habilidades conseguem ser melhor percebidos.

Fator 9- Desapego e Inovação =De acordo com o nono fator apontado, aqueles indivíduos que são desapegados materialmente tem um nível maior de CE, Gomes (2010) ressalta que estes indivíduos são pessoas que acompanham as tendências da moda e sempre estão em constante mudança quanto a novidades no que diz respeito ao estilo.

Nucleus, v.18, n.1, abr. 2021 


\section{CONSIDERAÇÕES FINAIS}

O presente estudo teve por objetivo validar, via Análise Fatorial (AF), o questionário elaborado para mensurar a presença de Capital Erótico (CE) em determinada população. Com base nos resultados, foi possível concluir que o CE pode ser mensurado pelas variáveis definidas neste estudo de acordo com 9 fatores principais, as variáveis mais relevantes para a composição do questionário foram capazes de explicar cerca de $70 \%$ dessas variáveis. A validez do questionário se mostrou muito próxima dos resultados apontados e encontrados por Hakim (2012), o que aponta semelhança e verdade nos fatores anteriormente apontados por ela em seus testes, e agora, comprovados novamente pela validação deste questionário.

A validação do instrumento para abordagem do CE como uma característica a ser explorada e aprendida, abre um leque de novas interrogações a respeito de sua existência e influencia para relacionamentos interpessoais. Assim, com uma margem de erro aceitável, o estudo revelou-se válido e consistente, evidenciando sua solidez para ser utilizado como instrumento de mensuração em estudos e análises futuras para identificar a presença desse Capital Erótico.

Pode-se concluir também que o CE não está relacionado exclusivamente com a beleza, mas que a beleza é um de seus nove componentes. Tais componentes devem ser vistos de forma holística, ou seja, a ausência ou minimização de um deles irá resultar num menor CE do indivíduo.

Os fatores relacionados aos (1) hábitos alimentares saudáveis e prática de atividade física, (2) habilidades sociais e apresentação, (3) atividade sexual e criatividade, (4) atração, carisma e beleza, (5) dinamismo e flexibilidade, (6) estilo e versatilidade, (7) bom humor, imagem e conforto, (8) presença e apresentação social e (9) desapego e inovação não são exclusivos e inertes a um grupo de pessoas, pois podem ser aprendidos, conquistados e mesmo perdidos. O indivíduo pode desenvolver seu CE concentrando esforços nestas 9 variáveis; por exemplo, melhorando seus hábitos alimentares buscando orientação com nutricionista, melhorar sua aparência com ajuda de profissionais da estética e cosmética ou mesmo desenvolver ideias inovadoras por meio da realização de curso ligados ao empreendedorismo.

Este estudo buscou contribuir para o conhecimento na medida em busca avançar nos estudos sobre o CE, em especial por meio da validação do instrumento para sua abordagem como uma característica a ser explorada e aprendida. Assim, com uma margem de erro aceitável, o estudo revelou-se válido e consistente, evidenciando sua aceitação para ser utilizado como 
instrumento de mensuração em estudos e análises futuras para identificar a presença desse Capital Erótico. Neste sentido, cabe ressaltar que o CE está presente nas pessoas, seja em maior ou menor grau, sendo assim identificar e quantificá-lo pode ser relevante ao indivíduo que busca aprimorálo para aplicar em seu progresso pessoal e profissional.

A limitação da pesquisa se deu pelo reduzido número de estudos e análises válidas devidamente publicados e reconhecidos acerca do tema abordado para elaboração da ferramenta (questionário) capaz de mensurar a presença de $\mathrm{CE}$ em determinado perfil. Apesar desse impasse que a princípio foi uma grande barreira para se conseguir informações concretas que seriam utilizadas, a pesquisa obteve um bom resultado, sendo considerado válido através dos resultados obtidos pela Análise Fatorial o instrumento testado.

Para estudos futuros, recomenda-se a aplicação do questionário levando-se em consideração os 9 fatores identificados na Análise Fatorial.

\section{REFERÊNCIAS}

AVELAR, C. F. P. de; VEIGA, R. T. Beleza não põe mesa? Entendendo a vaidade feminina utilizando a autoestima e a personalidade. In: ENCONTRO DA ANPAD, 35. Anais [...] 2011.

BOURDIEU, P. The forms of capital. In: Handbook of theory and research for the sociology of education. Nova York: Greenword Press, 1986. p. 241-58.

CABALLO, V. E. Manual de avaliação e treinamento das habilidades sociais. São Paulo: Santos, 2006.

CASTRO, A. L. de. Culto ao corpo e sociedade: mídia, estilos de vida e cultura de consumo. São Paulo: Annablume: Fapesp, 2003.

COSTA, J. F. O vestígio e a aura: corpo e consumismo na moral do espetáculo. Rio de Janeiro: Garamond, 2004.

ECO, H. A arte e a beleza na estética medieval. Portugal: Editorial Presença, 2011.

GIL, A. C. Como elaborar projetos de pesquisa. 4. ed. São Paulo: Atlas, 2002.

GIL, A. C. Métodos e técnicas de pesquisa social. 6. ed. São Paulo: Atlas, 2008.

GOLDENBERG, M.; RAMOS, M. S. O corpo da moda descoberto. In: A moda do corpo, o corpo da moda. São Paulo: Esfera, 2002.

GOMES, J. P. Beleza e carreira no Brasil: o significado da beleza para jovens executivas e seu papel no mercado de trabalho. São Paulo, 2010.

HAIR JR., J. F. et al. Análise Multivariada de Dados. 6. ed. Porto Alegre: Bookman, 2009. 
HAKIM, C. Capital erótico: pessoas atraentes são mais bem-sucedidas. A ciência garante. Tradução: Joana Faro. Rio de Janeiro: Best Business, 2012.

HAMERMESH, D. S.; BIDDLE, J. E. Beauty and the labour market. The American Economic Review, v. 84, n. 5, p. 1174-1194, dez. 1994.

HARPER, B. Beauty, stature and the labour market: a British cohort study. Oxford Bulletin of Economics and Statistics, v. 62, n. 1, p. 771-800, dez. 2000.

HUTCHESON, G. D.; SOFRONIOU, N. The Multivariate Social Scientist: Introductory Statistics Using Generalized Linear Models. London: SAGE, 1999.

KNOOP, G. C. A influência da mídia e da indústria da beleza na cultura de corpolatria e na moral da aparência na sociedade contemporânea. Encontro de Estudos Multidisciplinares em Cultura. Faculdade de Comunicação/UFBa, Bahia. Maio, 2008.

LÓPEZ BÓO, F.; ROSSI, M. A.; URZUA, S. The labor market return to attractive face. Evidence from a field experiment. IZA Discussion Papers, 6556, Institute for the study of Labor (IZA), 2012.

MADUREIRA, B. de. S.; NOVAES, J. de. V.; VILHENA, J. de. As Barbies do varejo: um estudo sobre os padrões estéticos do processo de seleção do comércio da moda carioca. Revista Eletrônica da Uerj. Polêmica, v. 15, n.1, p. 29-46, abr./maio/jun. 2015.

MALYSSE, S. Em busca dos Halteres- egos: olhares franceses nos bastidores da corpolatria carioca. In: M. Goldenberg (Orgs.). Nu e Vestido. Rio de Janeiro: Record, 2002.

MARTINS, Ivan; PEROSA, Teresa. A Beleza Compensa, Revista Época, p. 94. Edição Globo, 2011.

MARTINS, V. L. Valores estéticos e estigmas sociais ligados ao culto à beleza. Revista Científica Intraciência, v. 2, n. 1, p. 26-105, 2010.

MAUSS, M. As técnicas do corpo. In: MAUSS, M. Sociologia e Antropologia. Tradução: Paulo Neves. São Paulo: Cosac e Naify, 2003.

MINGOTI, S. A. Análise de dados através de métodos de estatística multivariada: uma abordagem aplicada. Belo Horizonte: Editora UFMG, 2005.

MORAES, V. Livro de sonetos. Rio de Janeiro: Sabiá, 1957.

MORESI, Eduardo (Org.). Metodologia da pesquisa. Brasília: Universidade Católica de Brasília, 2003.

PALLANT, J. SPSS Survival Manual. Open University Press, 2007.

PEREIRA, L. A. R.; SANTOS, G. E. Capital erótico no ambiente organizacional: a sua influência no processo seletivo e na empregabilidade. Revista de Ciências Gerenciais, v. 17, n. 26, p. 2134, 2013.

PESTANA, M. H.; GAGEIRO, J. N. Análise de dados para ciências sociais: a complementaridade do SPSS. 5. ed. Lisboa: Sílabo, 2008. 694 p. 
PRIORI, M. D. Corpo a corpo com a mulher: pequena história da transformação do corpo feminino no Brasil. São Paulo: Senac, 2000.

SAMPAIO, R. P. A.; FERREIRA, R. F. Beleza, identidade e mercado. Psicologia em Revista, v. 15, n. 1, p. 120-140, abr. 2009.

SIEBERT, R. S. As relações de saber-poder sobre o corpo. In: Corpo, mulher e sociedade. Campinas: Papirus, 1995.

SCHLOSSER, Adriano; CAMARGO, Brigido Vizeu.Percepção Sobre Beleza Física de Estudantes da Área de Exatas e Tecnológicas. Rev. Psicol. IMED [online]. 2019, vol.11, n.2, pp. 79-95. ISSN 2175-5027. http://dx.doi.org/10.18256/2175-5027.2019.v11i2.3281.

SONES, M. Human beauty, 2004.

WEEKS, J. Invented moralities: sexual values in an age of uncertainty. Columbia University Press, 1995. 